\title{
HISTÓRIA DO LIVRO E DA LEITURA E A 'VERDADE' NA HISTÓRIA ${ }^{1}$ Entrevista com Roger Chartier
}

History of book and reading and the 'truth' in History

\author{
Roger Chartier ${ }^{2}$ \\ Collège de France \\ École des Hautes Études en Sciences Sociales - EHESS/Paris
}

\begin{abstract}
RESUMO: Nesta entrevista, o historiador francês, Roger Chartier, nos apresenta reflexões acerca de duas das principais frentes de seu trabalho de pesquisa: um breve panorama da História da cultura escrita no Ocidente, a partir da relação entre as mudanças ocorridas na forma material do livro e as mudanças nas práticas de escrita e de leitura e o impacto da emergência das novas tecnologias digitais de produção escrita e editorial dos textos e de sua recepção; e suas reflexões quanto à especificidade da História, enquanto disciplina, e o valor de verdade de suas narrativas.
\end{abstract}

Palavras-chave: História cultural; Cultura Escrita; História e Verdade.

ABSTRACT: In this interview, the French historian, Roger Chartier, presents two aspects of his research work: i) a brief overview of the History of written culture in the West, and the impact of the emergence of new digital technologies for the written and editorial production of texts and their reception; ii) and the specificity of History, as a discipline, and the truth value of their narratives.

Keywords: Cultural History; Written Culture; History and Truth.

\footnotetext{
${ }^{1}$ Entrevista concedida no dia 13 de setembro de 2018, na Biblioteca comunitária da UFSCar, durante o V Colóquio Internacional de Análise do Discurso: Discurso e (pós)verdade.Efeitos de real e sentidos da convicção, realizado na Universidade Federal de São Carlos (UFSCar). Na ocasião, o entrevistado proferiu a conferência de abertura do evento, intitulada "Verdade da História, verdade da Ficção, verdade da Memória". A equipe responsável pela produção, transcrição, retextualização e revisão desta entrevista foi composta por Bianca Rapelli de Moraes, Gustavo Diniz, Johann Faigle do Nascimento, Nadia do Nascimento, Gabriela Gimenez e Lauro Damasceno, discentes do curso de Bacharelado em Linguística, e Luzmara Curcino, docente no Departamento de Letras e no Programa de Pós-graduação em Linguística da Universidade Federal de São Carlos (DL/PPGL/UFSCar). A entrevista contou ainda com o apoio técnico de Daniel Graciano, Lívia Damaceno, Jéssica de Oliveira e Simone Varella, discentes do Programa de Pós-graduação em Linguística. Esta entrevista, em sua versão audiovisual, está disponível em: <http://www.pnaic.ufscar.br/posts/view/Miscelaneas-RogerChartier>.

${ }^{2}$ Professor no Collège de France e na École des Hautes Études en Sciences Sociales (EHESS/Paris) e historiador reconhecido internacionalmente por suas pesquisas em História da cultura escrita no Ocidente, conhecido no Brasil especialmente por suas pesquisas sobre as representações das práticas de leitura.
} 


\section{Escrita e Leitura no passado}

Entrevistadores: Em vários de seus trabalhos, o professor avaliou o impacto das diferentes mudanças sofridas pelo livro, suas formas de escrita, produção e reprodução, sobre o modo como esses textos são recebidos e lidos ao longo da história. Quais foram as principais mudanças?

Roger Chartier: Em primeiro lugar, devemos considerar que a invenção do livro eletrônico, dos textos digitais, corresponde efetivamente a uma descontinuidade na história da cultura escrita, ou seja, a uma descontinuidade em relação ao livro, esse objeto tal como ainda o conhecemos hoje, em sua forma material, impressa, tal como esta que se encontra diante dos nossos olhos e ao alcance de nossas mãos nesta seção de livros infantis da Biblioteca Comunitária da UFSCar.

A circulação digital dos textos rompe com a forma tradicional do livro, tal como o conhecemos. Essa forma material do livro, que chamamos de códice ou de códex, emergiu e se estabeleceu no Ocidente entre os séculos II e IV da Era Cristã. Esse objeto que manuseamos no dia a dia, composto de folhas, com páginas numeradas, reunidas em uma mesma encadernação, quando de sua invenção, não correspondia ao livro tal como concebido e empregado até então pelos povos da Antiguidade, gregos e romanos, que liam os seus textos sob a forma de rolos, conhecidos também como 'volumen'. Esse objeto, como qualquer outro, implica gestos específicos em seu manuseio e formas de apropriação dos textos que eles portam totalmente diferentes daqueles que empreendemos e conhecemos em nossa relação como os livros sob a forma do códice. O rolo era um livro que não se podia folhear, pois não tinha folhas, que não se podia retornar facilmente a uma parte do texto, pois não dispunha de um índice, nem de indicação de número de páginas. Era um livro que não se podia portar consigo, nem fazer anotações simultâneas enquanto se lia, ou mesmo lê-lo em diferentes espaços ou em diferentes posições (sentado em uma mesa, deitado em uma cama), pois além de pesado exigia, em seu manuseio, que ambas as mãos o segurassem, e que fosse lido principalmente de pé.

Tal como essas descontinuidades nas formas do livro, e que tiveram implicações sobre nossos gestos e práticas de leitura, hoje em dia, com o livro eletrônico que vimos nascer recentemente também testemunhamos uma descontinuidade na história da cultura escrita, tanto relativa à forma do livro, dos textos, quanto em relação às práticas de escrita e de leitura. 
O livro eletrônico, sem dúvida, inaugura uma certa ruptura, uma dada revolução na leitura, o que por isso deve ser amplamente estudado e discutido.

Entre as mudanças ocorridas no passado na forma como os textos eram produzidos e lidos, a primeira diz respeito à capacidade de se ler de forma silenciosa e visual, como lemos hoje em dia. Ler em silêncio se impôs no Ocidente, no início da Idade Média, em contraposição a uma leitura oralizada, em voz alta, como prática mais comum, inclusive entre os leitores eruditos, os leitores considerados sábios. Essa mudança, da leitura oralizada para a leitura silenciosa, que se deu ao longo de séculos, deveu-se a algumas mudanças na escrita dos textos, tal como aquela relativa à inserção de brancos entre as palavras, entre os parágrafos, entre as partes de um texto, tornando-o mais legível.

No século XVIII, viu-se uma outra revolução na leitura, quando o modelo tradicional de leitura intensiva, empreendida diante de um repertório limitado de textos que eram por isso lidos e relidos, conhecidos de memória, decorados, cedeu lugar a uma leitura como a que realizamos hoje, extensiva, rápida, variada, graças ao acesso a muitos objetos de leitura alguns efêmeros, outros canônicos. Essa mudança correspondeu a vários fatores: um número maior de alfabetizados, a expansão significativa da oferta de títulos a baixo custo e acessíveis, uma melhor distribuição dessas produções.

\section{Escrita e Leitura na atualidade}

Entrevistadores: Entre essas mudanças, a revolução digital mais recente foi recebida por alguns como o fim dos livros e das práticas de apropriação desse objeto impresso, tal como o conhecemos, ao que o senhor nos apresenta uma ponderação menos trágica. Poderia, então, nos falar a esse respeito?

Roger Chartier: O tipo de descontinuidade nas práticas de leitura que testemunhamos hoje em dia, em relação aos textos acessados virtualmente, exige de nós, para sua compreensão, em primeiro lugar, reconhecer quais são os elementos mais fundamentais dessa ruptura no mundo digital. Acredito que o fator mais fundamental dessa ruptura é o da desvinculação de um objeto portador do texto e o próprio texto. Hoje, um texto que é produzido virtualmente não está vinculado a um único dispositivo, uma tela de smartphone, uma tela de computador ou de um tablet, diferentemente dos livros físicos desta biblioteca em que nos encontramos. Estes livros em nosso entorno são objetos materiais que estão vinculados a um único texto, 
são objetos que portam um texto, e tanto o livro quanto o texto são indissociáveis um do outro. O mesmo não ocorre com os textos que nos chegam por meio dos diferentes dispositivos eletrônicos. Diante das nossas telas, percebemos todos os dias que por meio delas podemos acessar e produzir variados textos, de extensões, formatos e destinações muito diversas, textos que queremos ler, textos que podemos escrever e difundir.

Outro exemplo de descontinuidade ligado à forma material do livro do passado e do livro do presente refere-se ao fato de que o livro impresso não era concebido para receber a escrita, ainda que o leitor pudesse facilmente escrever comentários, fazer anotações nas margens em branco da página ou ocupar os espaços em branco da composição tipográfica. Havia, no entanto, nessa forma do livro manuscrito ou impresso uma distinção entre objetos para ler e objetos para escrever. Isso tem se alterado no mundo digital, no qual testemunhamos uma certa continuidade entre as atividades de ler e de escrever.

Diante dessa mudança, foi inventada em inglês a palavra wreader, que seria a junção das ações de escrever (to write) e de ler (to read) conduzidas por um mesmo sujeito em relação a um texto. O leitor é escritor e o escritor é leitor, e a partir de um mesmo dispositivo. Essa designação wreader unifica os dois papéis em uma mesma pessoa, e a consequência disso é também o desaparecimento de uma série de práticas relativas à estrutura material do livro, tal como o conhecemos. Com essa mudança, se pode não ter ideia, por exemplo, da totalidade da obra, uma vez que sempre estamos diante de uma página em uma tela, de um texto de que não temos de antemão uma percepção da totalidade de sua extensão. Pode-se, com esse novo formato e forma de acesso virtual dos textos, extrair fragmentos, sejam eles uma página, um parágrafo ou um capítulo de um livro, de modo muito mais simplificado, e que podem circular de forma autônoma em relação ao restante do texto ou da obra, diferentemente do que ocorre com a forma material do livro ou do jornal impressos que contextualizam, dão de antemão uma ideia do todo textual.

No mundo digital, que é totalmente diferente do mundo impresso, pode-se confrontar, extrair, ler um fragmento sem ter de remeter parcialmente ou de maneira alguma à totalidade textual à qual ele pertence. Esse tipo de prática fica evidente com a multiplicação dos bancos de dados, dos acervos de enunciados extraídos de livros ou de diários, de onde se extraem fragmentos, que se autonomizam em certa medida, circulam individualmente e são usados com diferentes finalidades. Se pensarmos que a evolução da escrita segue nesse sentido, talvez a palavra "fragmento" até perca seu sentido, porque ela, tal como a concebemos ainda hoje, necessariamente supõe uma totalidade da qual faz parte, mas talvez no futuro ela equivalha a uma totalidade em si. 
Assim, somos testemunhas de todas essas diferenças radicais nos modos de produção e de recepção dos textos, que algumas vezes o vocabulário tenta domar ou limitar. Falamos, por exemplo, de uma 'página' da web, de um 'livro' eletrônico, mas os sentidos dessas palavras são totalmente diferentes da maneira como eram concebidas antes, pois a 'página' do livro impresso é uma entidade definitiva, que não se pode modificar. Já a 'página' da web pode se modificar permanentemente, quanto ao modo como aparece nas telas do computador, do tablet, do celular. Falamos em 'livro' eletrônico, mas "livro", no mundo tipográfico, significa tanto um objeto diferente de outros, como de uma carta, de um periódico, de uma revista, de um bilhete ou de um panfleto, como também significa uma obra, de um autor, um texto total e estável. Por exemplo, o livro de Umberto Eco é um romance escrito por Umberto Eco. Essa relação indissociável entre uma forma e um texto, no entanto, desapareceu no mundo digital, porque a definição material não tem mais o mesmo sentido. A definição do texto, com suas margens delimitadas, com seu começo e fim, pode ser desafiada ou, em certo sentido, até ameaçada pelo fenômeno de que estou falando, o da circulação dos fragmentos individualizados. É por essa razão que estamos falando de um mundo totalmente diferente, apesar das aparentes semelhanças.

\section{A escrita da História na era digital}

Entrevistadores: Que consequências essas mudanças relativas à digitalização na produção e circulação dos textos trazem, por exemplo, para a escrita da História?

Roger Chartier: Há uma série de consequências desse processo de mudança nas formas de produção e circulação dos textos. Se pensarmos no impacto do mundo digital em relação à História, como disciplina, percebe-se duas coisas: a transformação da condição da pesquisa, uma vez que hoje se tem acesso em grande parte a documentos digitalizados, transformados em fontes para um historiador. No entanto, isso requer da parte do historiador atenção. A forma de materialização desse documento por ele utilizado é aquela da tela do computador, e não mais a forma original de sua produção, e em muitas pesquisas é necessário ir ao formato original, ao documento do arquivo ou ao livro em sua forma material. Todos os livros têm o mesmo formato no mundo digital, ou seja, o formato da tela, e não mais o formato do livro, in fólio, in quarto, in oitavo, com páginas, em folhas. Assim, o acesso digital ao documento transforma as condições de trabalho do historiador, facilitando o acesso a uma série de 
documentos, mas é preciso que não se perca de vista a exigência, em grande parte dos trabalhos, de se voltar, em um momento ou outro, a consulta ao formato original.

A segunda transformação recai sobre as formas de demonstração, como a remissão a notas e a outros documentos, de que pode se valer o historiador na escrita de um texto sob a forma eletrônica. Ele pode mobilizar a hipertextualidade e, assim, organizar uma demonstração descontínua graças aos links que remetem para outros textos, fontes, elementos que são exteriores ao seu texto.

Por fim, uma outra transformação é aquela da leitura, já que o leitor tanto pode ler o texto do historiador quanto todos aqueles que o próprio historiador leu, caso haja a documentação acessível em forma digital, ou caso o historiador tenha produzido, ao mesmo tempo que seu próprio texto, a digitalização das fontes que usou e citou. Desta maneira, os critérios de realização da crítica, de validação ou de rejeição da demonstração historiográfica são reforçados pelo leitor, pela possibilidade que dispõe de ler o que o historiador leu como fonte ou como bibliografia. Em um livro de História tradicional, ou seja, impresso, todos esses elementos são colocados nas notas de rodapé, sejam eles fragmentos de documentos, sejam referências bibliográficas que o leitor geralmente não tem tempo e nem possibilidade de localizar. Assim, com essa mudança nas formas de produção e circulação dos textos de História ocorre uma transformação de sua escrita, de sua leitura e da pesquisa historiográfica.

Um primeiro aspecto a ser considerado em relação a essas transformações é o de que é necessário, tanto o escritor quanto o leitor, terem consciência da transformação que a digitalização opera sobre o documento digitalizado. Outro aspecto a se considerar é o de que até agora, apesar das tentativas de produção de livros digitais de História, explorando todo o potencial das relações hipertextuais, que permitiriam vários níveis da demonstração, que permitiriam a publicação dos documentos usados como fonte, os leitores que se interessam por História leem prioritariamente livros tradicionais, ou seja, livros de História impressos. É preciso considerar que tanto no Brasil, como na França, o livro eletrônico corresponde a somente $7 \%$ do mercado livreiro, ou seja, 93\% dos livros comercializados são ainda impressos. Em países como os Estados Unidos, o livro eletrônico corresponde a pouco menos de $20 \%$ do mercado de livros, percentual mais expressivo do que o do Brasil e da França, embora nos últimos anos se tenha observado que não houve um crescimento dessa porcentagem.

O que se observa é que há uma fidelidade à forma tradicional do livro, ao livro impresso. Portanto, todas essas possibilidades e potencialidades do livro digital não estão sendo ainda necessariamente aproveitadas. No mundo acadêmico, por exemplo, não se 
valoriza da mesma forma uma publicação eletrônica quanto se valoriza uma publicação impressa. Exemplo nítido disso é que os exemplares de teses enviados para as bancas ainda são impressos. Isso talvez se explique porque a maioria dos membros da banca têm mais idade, e pertencem a uma geração que não se sente ainda muito confortável (como é o meu caso) em ler 500 páginas na tela de um smartphone, mas também em função da perpetuação da ideia da maior "nobreza" do livro impresso, da "distinção" de que goza o livro impresso, que marca sua presença em um mundo cada vez mais digital.

\section{História e Verdade}

Entrevistadores: O professor poderia retomar algumas de suas reflexões sobre a História como uma disciplina com suas especificidades? O que diferencia a narrativa histórica, quanto a seu estatuto de verdade, de dizer verdadeiro, de outras narrativas como a memória ou a literatura?

Roger Chartier: Essa é uma pergunta complexa e importante. Em primeiro lugar, eu diria que a verdade produzida pela História se diferencia das demais por ser uma verdade de tipo científico. A narrativa histórica é o resultado de uma série de operações específicas, próprias da disciplina. Uma delas é a definição de um tema, em especial se considerarmos que o passado não é um tema em si mesmo. O modo de estabelecimento de um tema do passado, por si só implica uma razão, uma escolha, um posicionamento. O historiador também constitui seu objeto de pesquisa conforme uma metodologia, segundo a qual ele toma decisões quanto às fontes que vão lhe permitir responder à pergunta que esse tema e objeto suscitam, ele opera o tratamento dos dados selecionados, e ele exerce como pesquisador seu exercício crítico que permite compreender e descrever esses documentos remetendo-os às suas condições de produção. Esses documentos não foram escritos originalmente para comporem uma tese de História. Por isso, o que se faz na pesquisa histórica é uma conversão dos textos, dos documentos e dos livros, que circulam em um regime de uso, mas que o historiador decide transformá-los em fonte para responder a sua pergunta de pesquisa.

Além desses procedimentos, há também a decisão quanto ao modelo interpretativo. Há uma tensão bem conhecida na escrita da História entre dar ênfase às condições de determinação das ações dos atores do passado, não conhecidas por eles próprios, mas compreendidas pelo historiador quanto a esse tempo passado, que é o objeto sobre o qual o 
historiador trabalha; e entre enfatizar, como ocorre no campo da Demografia e da História social, o que os indivíduos do passado pensavam, desejavam e organizavam, suas estratégias, suas palavras. Disso advém essa tensão entre os conceitos empregados pelos historiadores acerca do passado - uma vez que não fizeram parte dele e se encontram em um tempo que lhes permite um recuo e um olhar externo em relação à época que estudam ou analisam - e o uso desses conceitos pelos próprios atores desse tempo. É preciso, portanto, compreender que há uma diferença entre um conceito científico e aqueles empregados pelos atores. Enfim, a escrita da História resulta desses procedimentos científicos de definição do objeto, de seleção dos documentos como fonte da pesquisa e das preferências ou decisões teóricas de um modelo interpretativo, que constituem um conjunto de operações historiográficas que são próprias da disciplina.

Assim, a verdade histórica deve ser entendida como um discurso produzido a partir de várias operações técnicas que referenciam a realidade do passado, definindo o objeto que se buscou compreender. Trata-se de uma modalidade de "verdade científica", evidentemente, com um matiz. No caso da História, particularmente quando se pensa em seu modelo explicativo adotado, se há interpretações que se pode rejeitar, algumas por serem consideradas como falsificações, outras como contraditórias na sua demonstração interna, outras como inadequadas enquanto compreensão das fontes, se mantém, no entanto, a ideia de que há uma pluralidade de interpretações legítimas, todas respeitando as regras de produção do conhecimento historiográfico, ainda que não atribuam aos fenômenos históricos interpretações únicas.

Há, pois, uma dificuldade para o estatuto científico dessas disciplinas das Ciências Humanas, já que nas Ciências 'duras', Exatas, se há variações, elas são históricas, ou seja, ao longo da 'evolução' da própria ciência. Não são variações contemporâneas umas das outras, simultâneas. Não há uma pluralidade possível de interpretações de um fenômeno físico ou químico. Uma variação, neste caso, pode ser um erro de interpretação, e como tal essa interpretação será rechaçada. Para as Ciências 'duras', Exatas, não pode haver uma coexistência de interpretações que sejam todas igualmente aceitáveis.

Assim, é preciso reconhecer a especificidade do estatuto científico das Ciências Humanas. O que resulta na diferença com outras 'verdades', produzidas por outros campos, mesmo entre áreas do campo das humanidades. Uma verdade literária, por exemplo, não supõe este tipo de operação que mencionei e que é próprio da construção da narrativa em História. Ainda que haja no texto literário notas de rodapé fazendo referência a documentos e ainda que seus autores se valham de técnicas de demonstração histórica, neste caso, o que 
teríamos seria um texto literário querendo imitar um texto histórico, criando a percepção de ser um texto histórico.

Hoje pela manhã, na conferência que ministrei neste evento ${ }^{3}$, fiz referência a um caso bem interessante e que exemplifica isso que acabo de dizer. Mencionei a invenção estética de uma biografia de um pintor catalão, Jusep Torres Campalans, que, de fato, nunca existiu, escrita por Max Aub, que foi conselheiro cultural em Paris. Nela o seu autor empregou todos os protocolos próprios de escrita de um livro de gênero biográfico e com objetivo histórico, de representação de uma realidade ocorrida, efetiva: ele emprega fotografias que seriam da família de Campalans; faz referência a dois periódicos parisienses que teriam publicado críticas da obra do pintor; faz referência ao catálogo de suas obras que teria sido publicado por um crítico irlandês; apresenta transcrições de conversas que ele, Max Aub, teria travado com o pintor de quem faz a biografia; etc. O livro mobiliza uma série de dispositivos de autenticação da realidade que narra, no entanto, a serviço de uma ilusão referencial particularmente poderosa e que enganou muitos leitores, embora o seu autor tenha deixado várias pistas, várias advertências irônicas de que não se tratava de um livro de História. Assim, o livro ficcional, literário, imita o livro de História, em suas operações de autenticação de seu dizer, e representa como real o produto que foi fruto da imaginação.

\section{Os discursos e sua 'vontade de verdade'}

Entrevistadores: Há, portanto, discursos que se pretendem verdadeiros e outros não, pois sua verdade consistiria em não serem verdadeiros, como no caso da Literatura. Alguns se instituem em função de sua "vontade de verdade" e são construídos com esse objetivo, como a História?

Roger Chartier: A "vontade de verdade" é um conceito foucaultiano. Ele está presente não somente em seu livro A vontade de saber ${ }^{4}$, quando ele de fato tematiza essa questão, mas também em sua conferência A ordem do discurso ${ }^{5}$. Nesta ele levanta a questão de saber como se deu, sempre e ao longo da história, a exclusão de certos discursos em nome de certas

\footnotetext{
${ }^{3}$ A publicação do texto da conferência sairá em breve, sob o título "Verdade e suas comprovações: seu estatuto e suas formas na Retórica, na Literatura, na Memória e na História", em livro organizado pelos professores da UFSCar Luzmara Curcino, Vanice Sargentini e Carlos Piovezani, juntamente com os textos das demais conferências do V CIAD.

${ }^{4}$ Cf. Foucault (2014).

${ }^{5}$ Cf. Foucault (2011).
} 
"vontades de verdade" que regeram nossa "vontade de saber". Ele discute as razões de certos deslocamentos quanto ao que se podia instituir como um "discurso verdadeiro" se comparados os séculos XIX e XVI, por exemplo, quanto as operações empregadas para estabelecer a verdade ("ver, em vez de ler, verificar, em vez de comentar" nos apresenta distinções fundamentais entre os vários discursos que são produzidos e que circulam entre nós, graças a certas formas materiais (os livros, por exemplo) e a certas instituições (a pedagogia, por exemplo) que exercem uma espécie de controle/coerção sobre os dizeres e sua recepção: a distinção entre loucura e razão, entre o dizer permitido e o censurado e entre aqueles que se pretendem verdadeiros e aqueles que não.

Para Foucault, nessa perspectiva, a "vontade de verdade" é uma característica própria de certos discursos, que é inteiramente definida discursivamente. Quando falamos sobre a "vontade de verdade" da História, estamos falando de uma "vontade de verdade" em sua dimensão epistemológica, ou seja, de uma intenção de produzir um discurso que seja uma representação a mais adequada possível de um objeto histórico, de um objeto a que a História se propôs interpretar. Daí a importância do conceito de "representação", porque o historiador não escreve o passado, mas sim a representação de um passado, e o faz por meio de técnicas de pesquisa e com o uso de uma estratégia interpretativa com a pretensão de que esse discurso possa tornar presente o ausente, possa tornar presente o passado.

Assim, é preciso separar a "vontade de verdade" como característica discursiva, que não tem como preocupação a adequação entre essa verdade e o real, mas sim com a intenção de ser/parecer um discurso verdadeiro, da "vontade de verdade" segundo uma perspectiva epistemológica, que se preocupa com a adequação entre o discurso proferido sobre uma realidade e a própria realidade, seja ela qual for. Podemos, neste caso, falar do discurso científico sobre um fenômeno físico ou químico, ou de uma descrição de um passado feita com distanciamento em relação a ele.

Embora se possa depreender, em especial em seu livro A ordem do discurso, uma presença mais marcada da "vontade de verdade" como própria do discurso, de seu funcionamento, o que ecoa uma referência nietzschiana ${ }^{7}$ que é tão forte na obra dele, é preciso considerar que quando Foucault escrevia seus livros, ele planejava produzir um discurso mais adequado que outros discursos à realidade que descrevia: a loucura, a clínica e o cárcere. Essa posição, filosoficamente nietzschiana, só é possível quando se está produzindo um livro de História como Foucault, em que filosofia e história se imbricam. Suas perguntas de pesquisa

\footnotetext{
${ }^{6}$ Cf. Foucault (2011, p. 16).

${ }^{7}$ Cf. Nietzsche (2008).
} 
são próprias desse imbricamento: Quando nasceu a 'prisão' como um modo dominante de repressão? Quando nasceu a 'loucura' e o seu distanciamento de nós que éramos racionais? Quando nasceu a medicina como clínica? Todas essas são perguntas históricas e, portanto, as respostas de Foucault a essas perguntas visam a produzir argumentos que as responderão mais adequadamente do que as outras respostas dadas antes e por outros a essas perguntas.

\section{Referências}

FOUCAULT, Michel. A ordem do discurso: aula inaugural no Collège de France, pronunciada em 2 de dezembro de 1970. 21 ed. São Paulo: Edições Loyola, 2011.

FOUCAULT, Michel. História da sexualidade (v. I): a vontade de saber. 9 ed. Rio de Janeiro: Editora Paz \& Terra, 2014.

NIETZSCHE, Friedrich Wilhelm. Além do bem e do mal. Porto Alegre: Editora L\&PM, 2008.

Recebido em: 12 de fevereiro de 2020.

Aceito em: 17 de abril de 2020. 